\title{
Dois Monumentos a Carlos Gomes na Primeira República
}

\author{
Fanny Lopes ${ }^{1}$ \\ DOI 10.20396/eha.vil4.3416
}

Em 16 de setembro de 1896, a morte do compositor campineiro Antonio Carlos Comes (18361896), dava início a um dos episódios mais marcantes da primeira década republicana no Brasil. Os ritos fúnebres de Comes, monumentais e públicos, desdobraram-se em diversas homenagens por todo o país. O músico faleceu no estado do Pará, mas o sepultamento seria em sua cidade natal, após pedido de ilustres de São Paulo, endossado pelo próprio presidente, Campos Salles (18411913). O périplo de seu corpo prolongou o luto: cerimônias litúrgicas foram realizadas em Belém, no Rio de Janeiro e em Santos, antes que seu corpo seguisse em cortejo para Campinas, com mais alguns pontos de parada².

O culto cívico dos grandes homens era fundamental para a cultura liberal e nacionalista em construção na jovem república. A comoção em torno da morte do gênio artístico poderia servir de elo, apaziguando, mesmo que temporariamente, desavenças. Em uma crônica, Machado de Assis afirmava:

A maior das notícias para nós, a única nacional, não preciso dizer que é a morte de Carlos Comes. O telégrafo no-la deu, tão pronto se fecharam os olhos do artista e deu mais a notícia do efeito produzido em todo aquele povo do Pará, desde o chefe do Estado até o mais singelo cidadão. A triste notícia era esperada - não sei se piedosamente desejada (...). Atentai, mais que tudo, para esse sentimento de unidade nacional, que a política pode alterar ou afrouxar, mas que a arte afirma e confirma, sem restrições de espécie alguma ou desacordos, sem contrastes de opinião. A dor aqui é brasileira ${ }^{3}$.

Era evidente que os feitos de Carlos Comes estariam sempre intrinsecamente ligados ao Império e a Pedro II, seu benemérito. Por isso, a sociedade republicana hesitou em apoiar o compositor, quando, adoentado e falido, buscava uma posição na capital ou em Campinas - o que

\footnotetext{
1 Doutoranda em História, como orientação do prof. Dr. Jorge Coli, pelo Instituto de Filosofia e Ciências Humanas da Universidade Estadual de Campinas. Bolsista CNPq.

2 Sobre o tema, foram publicados artigos frequentes desde o mês de julho quando se anuncia os seus problemas de saúde. Destaco: "Carlos Comes", in: O Paiz, Rio de Janeiro, 13 out 1896, p.1. Também a sequência de telegramas publicados no mesmo jornal, em 28 out 1896, p.1. Em um deles, lê-se: "Para avaliar a concorrência ao enterro de Carlos Comes basta dizer que cada carro era alugado por $200 \$$ e que se pagou por uma janela $100 \$$ para assistir a passagem do préstito. Quando este desfilou a cidade literalmente ficou deserta....

3 Originalmente publicado na revista A Semana, 20 de setembro de 1896. ASSIS apud OLIVEIRA, Emerson D. G. de. Os últimos dias de Carlos Comes: do mito gomesiano ao nascimento de um acervo. Revista CPC, São Paulo, n.4, maio/out. 2007, p.87-113.
} 
explica por que Comes faleceu no Pará, onde foi recebido pela oligarquia da borracha, que buscava consolidar-se nacionalmente. Mas as dissonâncias foram, em grande medida, silenciadas pelos meses de agonia que antecederam a morte do maestro, e por todo o ritual que se seguiu. A mensagem de Machado de Assis, neste contexto, apelava à afetividade e ao orgulho pela excepcionalidade, forças aglutinadoras fundamentais para a formação cívica ${ }^{4}$.

Como figura pública, o músico teve sua trajetória entrelaçada a disputas político-simbólicas que foram revigoradas após sua morte. Neste ponto, a arte teria um papel fundamental, dando forma a diferentes apropriações narrativas acerca do maestro, que compõem uma considerável iconografia republicana de Comes 5 . Neste artigo terão destaque dois monumentos públicos erigidos em celebração ao compositor, respectivamente, nas cidades de Campinas e de São Paulo. O primeiro, inaugurado em 1905, é obra do escultor brasileiro Rodolfo Bernardelli (1852-1931). Já o monumento paulistano é de autoria do italiano Luigi Brizzolara (1868-1937) e foi inaugurado em $1922^{6}$ [Fig. 1 e 2].

Deve-se ressaltar o fenômeno de propagação da estatuária pública na Primeira República, entre outros aspectos, efeito da descentralização federalista, que multiplicou os agenciamentos dos monumentos entre as diversas oligarquias estaduais e municipais - em oposição a centralização monárquica. Neste contexto, a celebração cívica significava uma oportunidade de representação social dos indivíduos e valores dessas sociedades, e a ereção de monumentos tornou-se num meio crucial para este fim. Com um percurso que se iniciava com uma subscrição pública para financiar a obra, culminando em pomposas cerimônias de inauguração.

É importante ainda ter em mente que a valorização da escultura pública era um fenômeno com sentidos e desdobramentos semelhantes em diversos países, irradiando-se como modelo a partir da consolidação dos estados nacionais europeus do século XIX. Este fato deu origem a uma produção transnacional, marcada pela intensa circulação de artistas - estudando e trabalhando no exterior -, de modelos estéticos, de técnicas e mesmo de obras escultóricas, já que muitos monumentos americanos, por exemplo, foram executados em fundições e marmorarias europeias. Ana-

\footnotetext{
4 Empresto o termo orgulho pela excepcionalidade, no artigo do historiador Paulo Knauss, no qual ele analisa o caráter afetivo como elemento estrutural para a promoção do culto cívico na Primeira República. KNAUSS, P. O descobrimento do Brasil em escultura: imagens do civismo. Projeto História, São Paulo, v. 20, 2000, p. 178. Acessado em 11 out 2019. Disponível em: https://revistas.pucsp.br/revph/article/view/10810. 5 Representaç̃̃es do compositor e sobre sua obra foram produzidos em diversos contextos. Foram frequentes nos planos decorativos dos teatros brasileiros, por exemplo. No Pará, a pintura histórica Os últimos dias de Carlos Comes, executada pelos italianos Domenico de Angelis e Giovanni Capranesi, em 1899, transformou a narrativa sobre a visitação ao leito de morte do compositor num emblema da oligarquia republicana paraense. Muitos artistas do dedicaram obras a Carlos Comes. Podemos citar Antônio Parreiras, Décio Villares, Henrique Bernardelli, a medalha de do gravador Augusto Cirardet, dentre outros. Sobre o tema, OLIVEIRA. Op.cit.

6 texto que se segue, analisando estes dois monumentos, é uma revisão e ampliação de um tópico desenvolvido em minha dissertação de mestrado. LOPES, Fanny. Cenografia e Paisagem Urbana: um estudo de caso na cidade de São Paulo. Dissertação (Mestrado em História) - Instituto de Filosofia e Ciências Humanas, Universidade Estadual de Campinas, Campinas, 2012.
} 


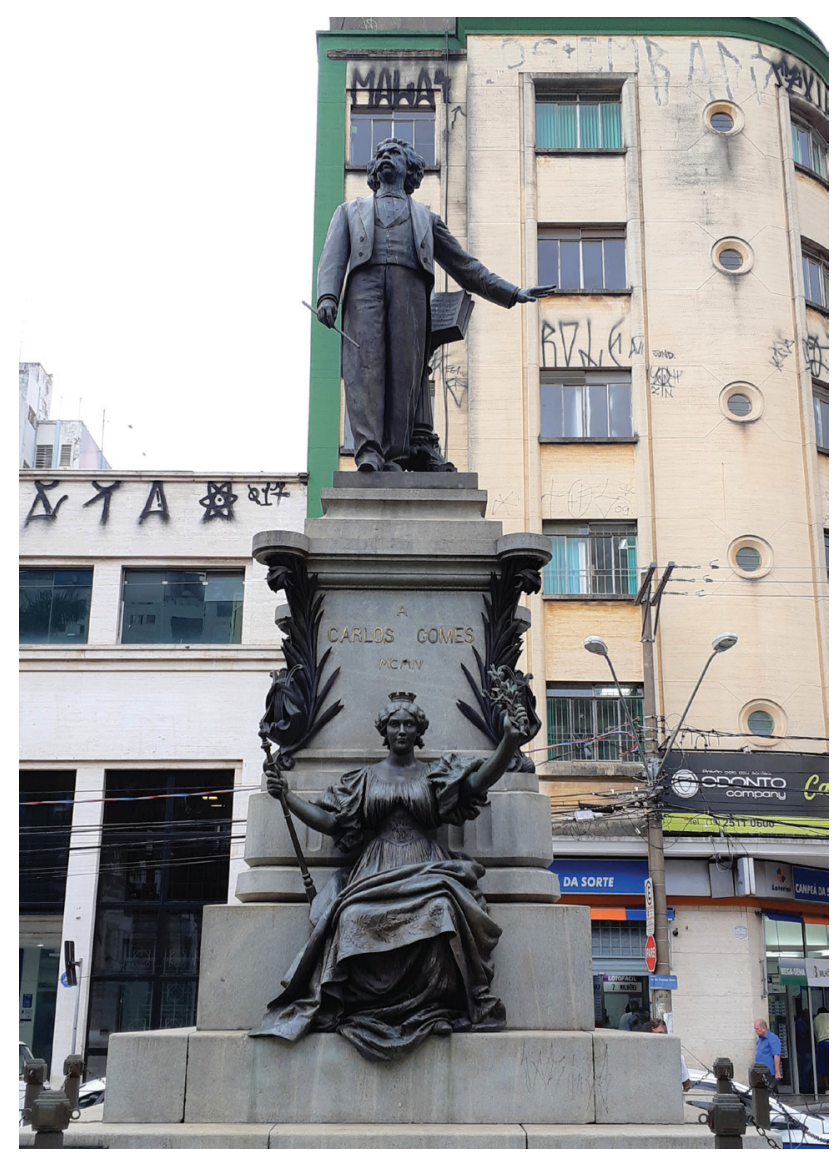

[Figura 1]

Rodolfo Bernardelli. Monumento-Túmulo a Carlos Comes, 1905.

Bronze e granito, Largo do Carmo, Campinas.

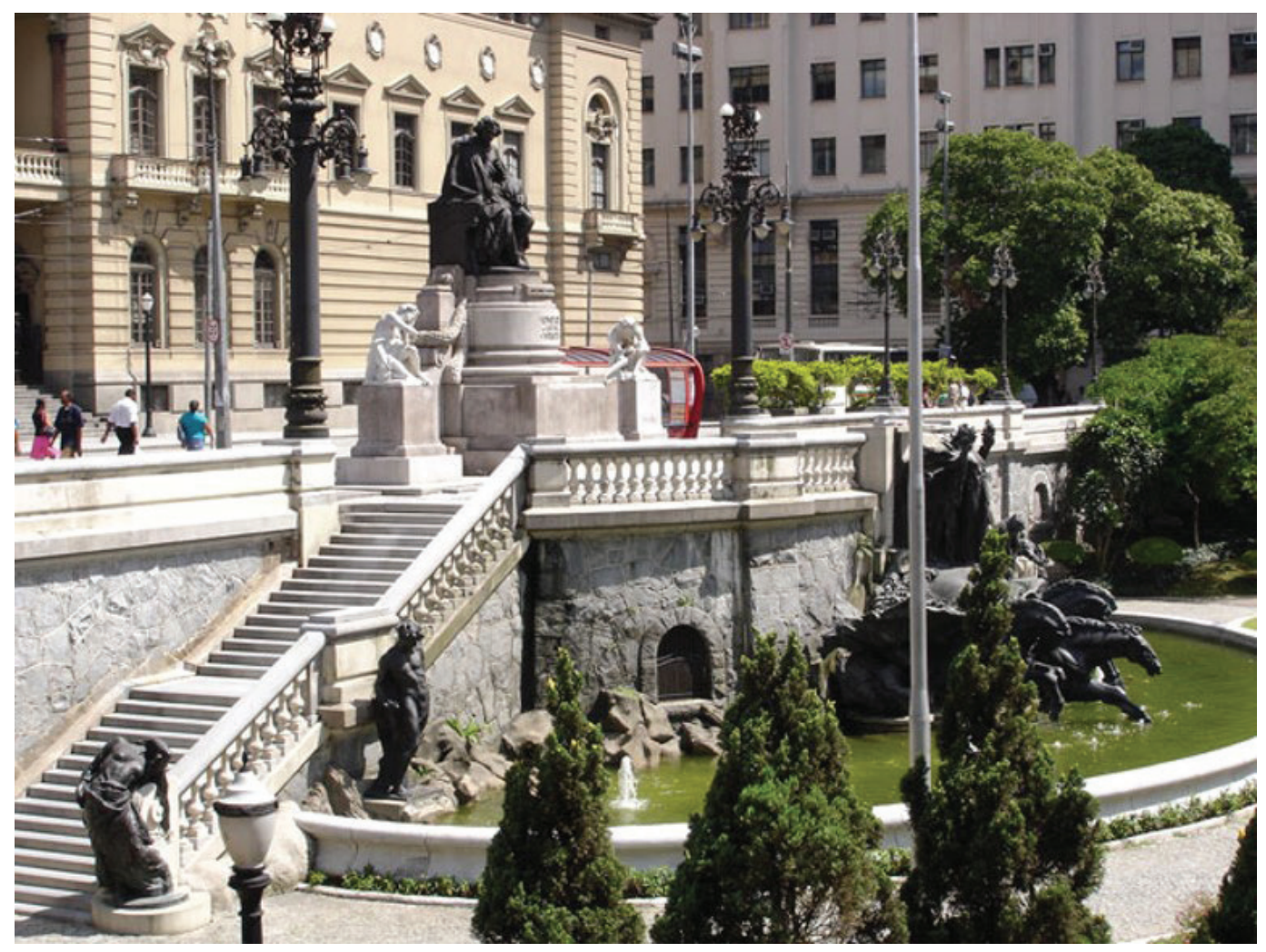

[Figura 2] Luigi Brizzolara. Vista lateral do Monumento a Carlos Comes, 1922.

Bronze, mármore, granito rosa, Praça Ramos de Azevedo (Parque do Anhangabaú), São Paulo. 
lisando os dois Monumentos a Carlos Comes são nítidos os indicativos deste cenário de circulação transnacional, que, tendo em vista o caráter eminentemente nacionalista investido nestes monumentos, tornou-se fonte de conflitos e contradições.

\section{O Maestro e a Campinas de Bernardelli}

As relações entre a obra de Rodolfo Bernardelli e a escultura italiana da segunda metade do século XIX foram bem demonstradas por Maria do Carmo Couto da Silva em suas pesquisas sobre o escultor7. Tendo estudado no ateliê de Giulio Monteverde (1837-1917) em Roma, Bernardelli contribuiu para estreitar os laços entre os italianos e a Academia Imperial de Belas Artes, da qual tornou-se professor ${ }^{8}$. Por outro lado, ao longo da primeira república, como diretor da Escola Nacional de Belas Artes, o escultor se consolidou como figura central para a produção artística brasileira, exercendo domínio quase absoluto sobre as encomendas monumentais da capital. Como apresenta a estudiosa Anna Carboncini, a força da Escola e a atuação de Bernardelli, levava os escultores estrangeiros e imigrantes a buscar atuação, sobretudo, em outros estados brasileiros ${ }^{9}$.

O caso do Monumento a Carlos Gomes de Campinas é bastante sintomático. Inicialmente propôs-se um concurso para a criação do monumento. Sabemos que diversas maquetes foram expostas na vitrina da loja Casa Livro Azul no mês de setembro de 1898. Pelo menos dois artistas imigrantes italianos apresentaram propostas: Giuseppe Berna, discípulo também de Monteverde, que havia fundado uma marmoraria no Brasil-, e Virgílio Cestari, autor do Monumento a Tiradentes, inaugurado em Ouro Preto, em 1894. Contudo, numa crítica de 1898, lê-se que as maquetes não impressionavam e que a comissão organizadora havia escrito "mais uma vez" apelando ao sr. Rodolfo Bernardelli para que participasse da contenda. Teria, por fim, o escultor respondido que não participaria de concurso com "qualquer um", pois "desde que aqui me acho não tem havido artista

7 Em particular sua tese de doutoramento. SILVA, Maria do Carmo Couto da. Rodolfo Bernardelli, escultor moderno: análise da produção artística e de sua atuação entre a Monarquia e a República. Tese (doutorado em História) - Instituto de Filosofia e Ciências Humanas, Universidade Estadual de Campinas, Campinas, 2011.

8 O historiador Alberto Martín Chillón apresenta um dado bastante interessante quanto aos escultores nomeados membros correspondentes e honorários na Academia Nacional de Belas Artes (AIBA). As nomeações aconteceram maciçamente em duas datas: 1857 e 1876, com outros nomes avulsos em datas intermediárias. Entre os escultores, no primeiro momento, as nomeações são majoritariamente francesas, com um único nome italiano entre 18 membros. Em 1876, a situação é inversa: entre 11 indicados, apenas um é vinculado à Escola de Belas Artes de Paris enquanto 7 italianos despontam na lista, professores em Luca, Roma, Florença e Nápoles. O pesquisador reforça a presença de Rodolpho Bernardelli no Instituto Romano nestes anos como possível determinante, inclusive Giulio Monteverde estava entre os nomeados. CHILLÓN, A. M. A escultura e seu ofício no Brasil do Segundo Reinado. Tese (Doutorado em Artes) - Centro de Educação e Humanidades da Universidade do Estado do Rio de Janeiro, Rio de Janeiro, p.298-299.

9 CARBONCINI, Anna. Virada do Século - a escultura italiana em São Paulo. In: Dezenovevinte: uma Virada no século. São Paulo: Pinacoteca do Estado, 1986, p.11-15. 
estrangeiro e menos nacionais que tenham executado esse gênero de trabalho"10. Portanto, após negociações mediadas por Ângelo Agostini, ele recebeu a incumbência pelo projeto e o concurso foi cancelado.

Entre os membros da comissão executiva para o Monumento a Carlos Comes estavam César Bierrenbach (1872-1907), jurista e escritor campineiro, com quem Bernardelli pareceu estreitar laços, como apontam as correspondências trocadas por eles durante o processo de ereção do monumento. A este artigo não cabe aprofundar a análise dessas missivas, embora seja interessante destacar que frequentemente Bernardelli mencionava o orçamento apertado e os muitos inimigos do projeto. Em janeiro de 1904, rebatendo os temores de Bierrenbach quanto à recepção da obra, o escultor escreveu:

Será um grande prazer para nós os devotos, o dia em que entregarmos ao pasto das feras esse modesto, mas sincero monumento. Que importa os Lobos!!! Nunca vi lobos morderem pedra e bronze... ${ }^{11}$

Estas correspondências registraram também um interessante diálogo acerca da escolha da fundição na qual as estátuas seriam preparadas. Lembrando as restrições orçamentárias, Bernardelli sugeriu que a execução fosse feita na Fundição Artística de São Paulo, onde atuava como responsável Pasquale De Chirico (1873-1943), artista imigrante por quem o escultor italiano Achille D’Orsi (1845-1929) havia escrito a Bernardelli pedindo boa acolhida no Brasil. Mas a decisão final foi pela execução na França. A desconfiança da elite brasileira quanto à indústria nascente no país se mescla aqui com a predileção histórica pelos artigos europeus, como se nota na colocação de Bierrenbach: "não há certeza de que em Paris o trabalho é melhor que em São Paulo? Pelo amor de Deus, não nos exponha a erigirmos na praça pública um aleijão. Cumpre desconfiar!”. Apenas o brasão de cidade e os demais ornamentos e letreiros do monumento foram executados em São Paulo, no Liceu de Artes e Ofícios, sob responsabilidade de outro imigrante italiano, Amadeo Zani (1869-1944), seguindo as estátuas principais do conjunto para a gigante Fonderie Thiébaut na França.

Sobre a encomenda, propunha-se a criação de um monumento túmulo para abrigar os restos mortais do compositor. A obra inicialmente destinava-se ao Cemitério da Saudade, mas posteriormente optou-se pela transferência para um logradouro público. Em um estudo em gesso pre-

\footnotetext{
10 Idem, p. 13.

11 Rodolfo Bernardelli, correspondência para Bierrenbach. 25 de janeiro de 1904. Coleção de documentos da Pinacoteca do Centro de Ciências, Letras e Artes de Campinas.
} 
servado no Centro de Ciências, Letras e Artes de Campinas, vemos o corpo de Comes, que repousa amparado por uma afável figura angelical [Fig. 3, 4 e 5]. O realismo da representação do retrato no leito de morte, soma-se a uma visão poética e mística da própria mortalidade, que refletia o melhor da tradição da escultura tumular italiana do período, a exemplo da própria obra de Monteverde ${ }^{12}$.

Mesmo com o deslocamento do projeto para o espaço urbano, o escultor se mantinha atento ao fato daquele monumento servir também como o cenotáfio de Carlos Comes. Pode-se dizer que os primeiros projetos de Bernardelli eram investidos de certa espiritualidade e intimismo que encontra diálogos evidentes com a tradição dos monumentos tumulares oitocentistas.

Uma série de maquetes reproduzidas na revista Renascença ${ }^{13}$ registram algumas das propostas rejeitadas pela comissão responsável pelo monumento [Fig. 6]. Entre as variantes, algumas foram compostas apenas com um busto do compositor, inserido em plintos que remetem formalmente a um altar, explicitando o culto cívico. O busto vinha emoldurado por basta coroa de louros e ladeado por duas alegorias, representando o Drama e a Música, que lamentavam a morte de Gomes. Outras duas versões, ainda com forte diálogo com a tradição da arte tumular, inseriam este busto sobre um mausoléu de falsa arquitetura com uma porta em destaque, que evidenciava a passagem entre o mundo dos vivos e dos mortos - em uma delas, Bernardelli inseri novamente um elegante anjo monteverdiano, de asas enormes, que guardava a porta entreaberta. Um último estudo destacava-se: era um retrato de Gomes como compositor, ele aparece de pé e vestindo pijamas, diante de um piano aberto, olhos erguidos e pena na mão. Inclinada sobre o piano, uma figura alegórica, novamente alada, representando a inspiração e glória do músico.

Estas maquetes demonstravam, sobretudo, a vontade de Bernardelli de inovar, aproximandose de tendências menos difundidas na escultura monumental pública. A originalidade do projeto com o piano é apontada pelo crítico Manuel de Souza Pinto, como a principal causa para sua rejeição por parte da comissão do monumento "pelo receio do choque entre a fantasia do escultor e o culto da cidade natal ao gênio"14. O texto do crítico reflete a frustração do próprio escultor, forçado a optar por uma visão que considerava inferior.

O Monumento a Carlos Gomes de Rodolfo Bernardelli foi inaugurado, finalmente, em 02 de

\footnotetext{
12 SIIVA, Maria do Carmo C. da. Op. cit., p.115-116.

13 O autor menciona sete maquetes foram desenvolvidas para o monumento, afirmando que "Bernardelli foi obrigado a modificar muitas vezes o seu plano". É importante destacar que a revista era dirigida pelo irmão do escultor, Henrique Bernardelli, e que é bastante evidente que o artigo contou com o apoio direto do escultor. PINTO, Manuel de Souza. O Monumento a Carlos Gomes, in: Renascença, Rio de Janeiro, ano II, n. 13, agosto de 1905, p. 46.

14 Idem, p. 51
} 


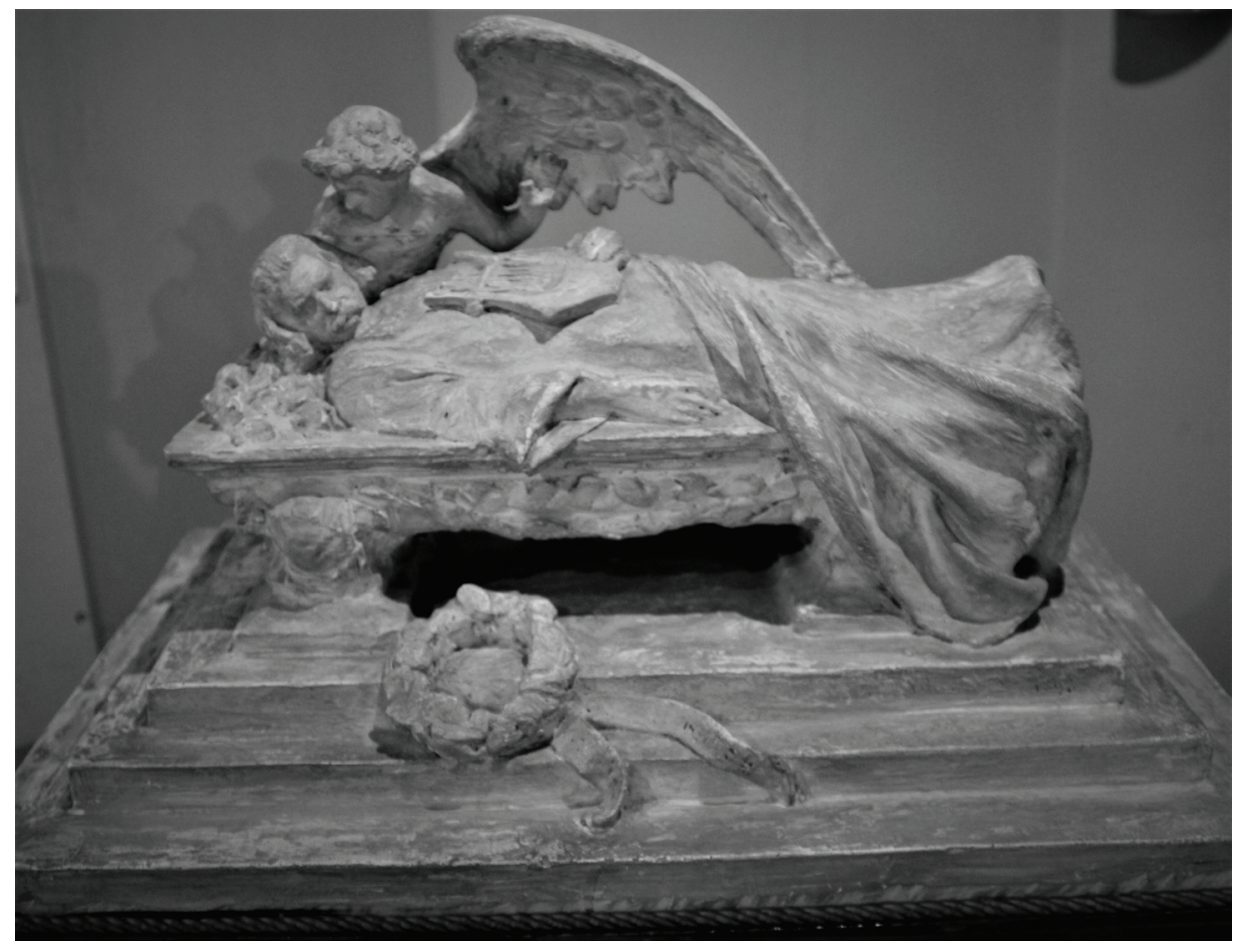

[Figura 3] Rodolfo Bernardelli. Maquete para Monumento a Carlos Comes, c. 1900. Cesso, Centro de Ciências, Letras e Artes de Campinas.
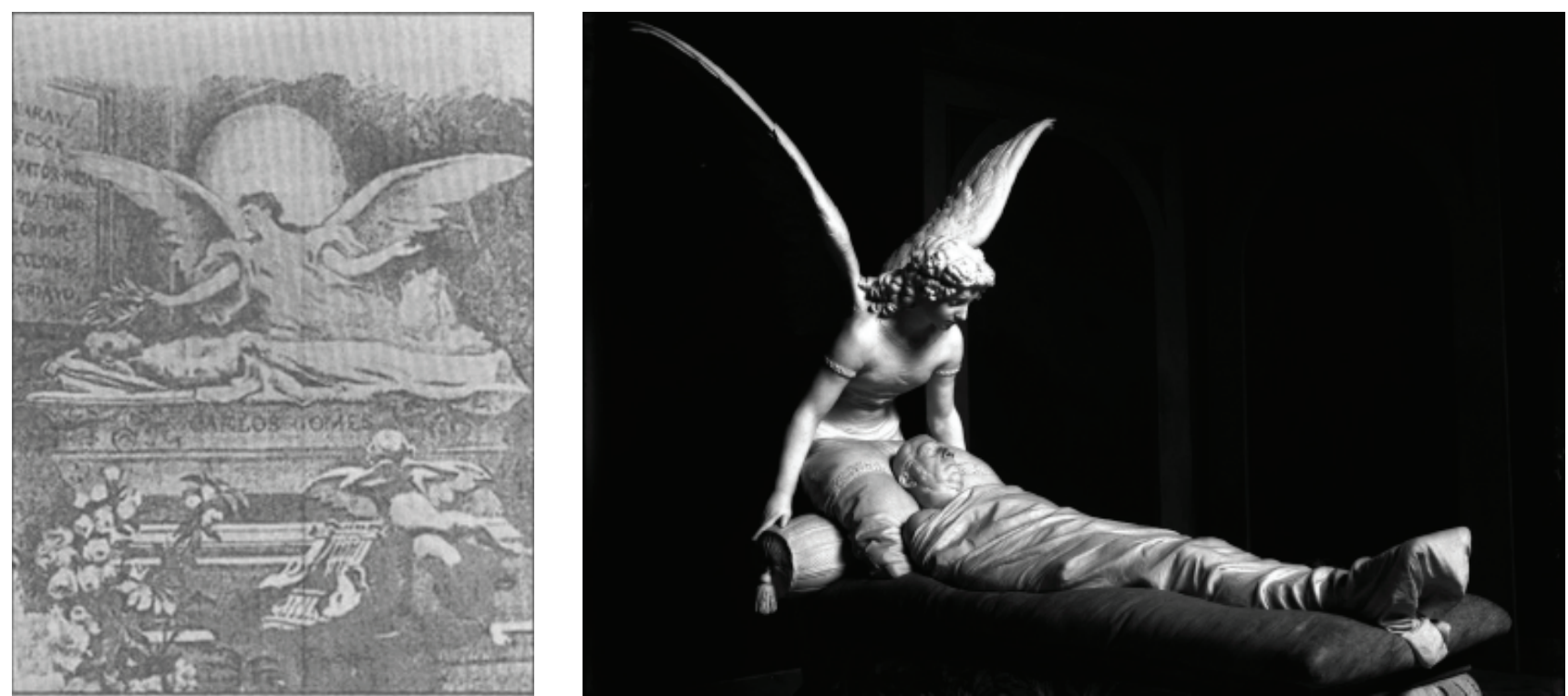

[Figuras 4 e 5] Duas imagens para refletir sobre as referências de Bernardelli. A primeira é uma alegoria publicada na capa do Jornal A Prinvícia do Pará, 17 de setembro de 1896, um dia após a morte do compositor. A segunda é uma estátua fúnebre de Giulio Monteverde. Túmulo do Conde Massari, 1876.

Fotografia de Pietro Poppi (1890). Fundo Fotografia dell'Emilia, Fondazione Cassa di Risparmio in Bologna. 


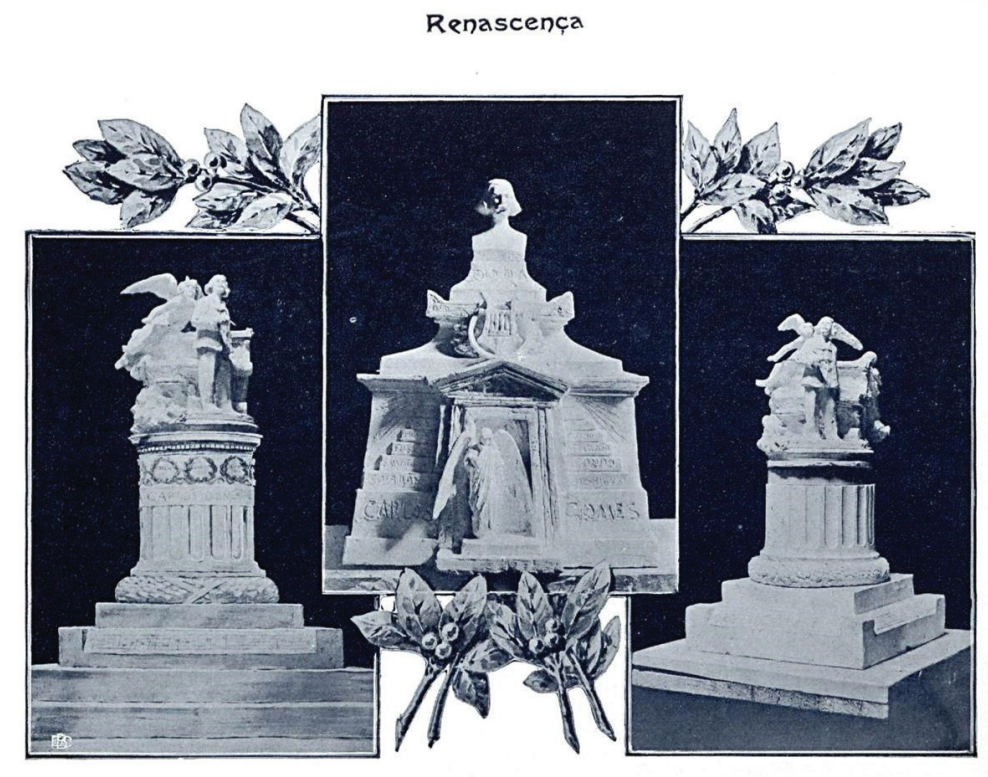

Projectos

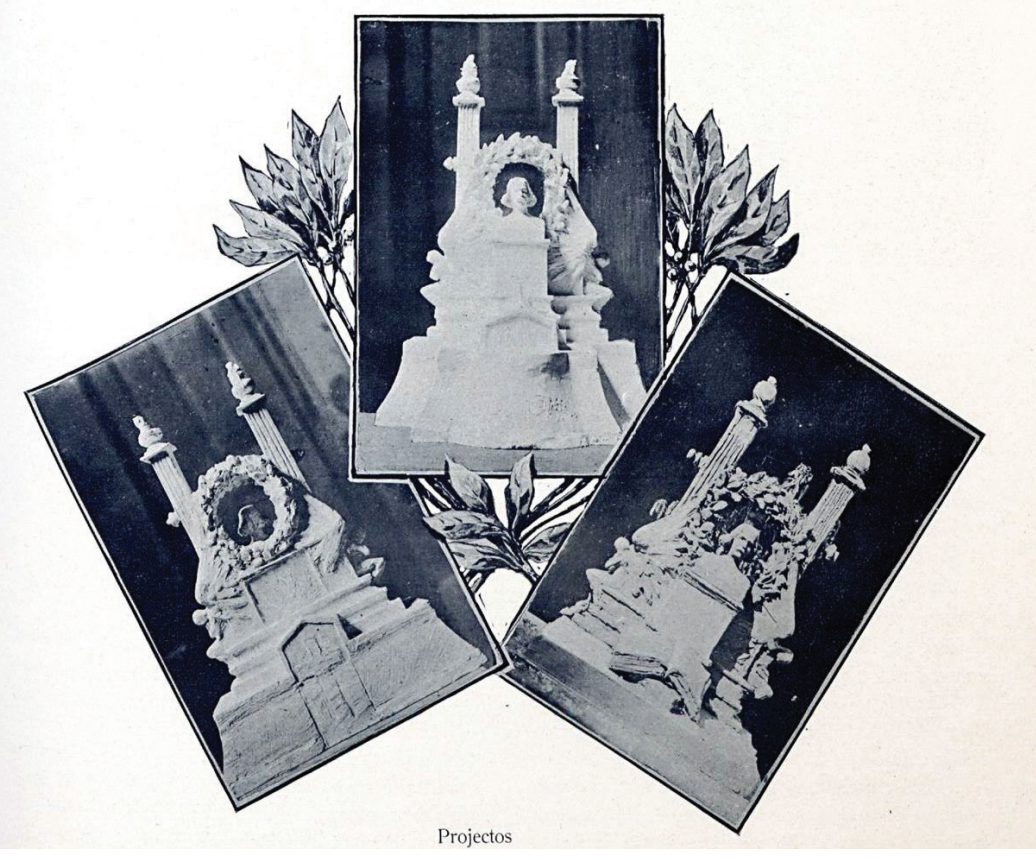

[Figura 6] Rodolfo Bernardelli. Reprodução das maquetes de estudo para o Monumento a Carlos Comes.

In: PINTO, Manuel de Souza. O Monumento a Carlos Comes, in: Renascença, Rio de Janeiro, ano II, n. 13, agosto de 1905 .

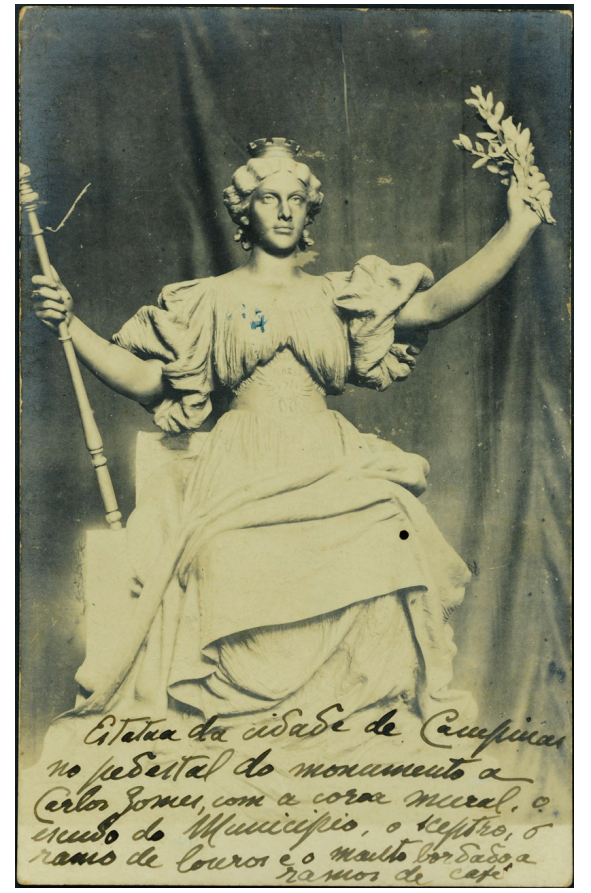

[Figura 7] Rodolfo Bernardelli. Alegoria a Campinas - Monumento a Carlos Comes, 1905.

Fotografia, Coleção Carlos Comes, Museu Imperial. 
julho de 1905. É composto por duas figuras principais: uma alegoria a Campinas e um retrato de Carlos Gomes como maestro, posicionado sob um pedestal de base quadrangular em granito, ornamentado em suas arestas por arranjos de palmas e liras. Como bem colocou Maria do Carmo Couto da Silva "a estátua de Carlos Comes nos permite imaginar, por meio da expressão do músico, ao observar o seu rosto e a sua postura, um concerto invisível"15. Atrás do maestro, uma estante suporta um enorme livro de partituras em homenagem a toda sua obra.

Considerando a versão da maquete com o piano e a obra desenvolvida, é possível notar em ambas a busca de Rodolfo Bernardelli por um instante significativo ${ }^{16}$, evidenciando o sentido narrativo destas estátuas. Se o piano compunha um cenário mais dramático e peculiar, a presença da estante e a batuta empunhada, na versão concretizada, demonstram uma vontade cênica semelhante.

Sabe-se que inicialmente o projeto considerava uma alegoria a Glória, que estaria inclinada em direção ao pedestal, escrevendo o nome do músico ${ }^{17}$. Essa figura foi logo substituída pela representação de Campinas, em função do endereço ao qual o monumento foi destinado, uma praça recém aberta no local antes ocupado pelo antigo Paço Municipal, Fórum e Cadeira, marco zero da cidade. A Campinas de Bernardelli, bastante hierática, senta-se com firmemente em frente ao conjunto [Fig. 7]. Apoia uma das mãos a um cetro e, na outra, ergue ramos de louro em homenagem ao compositor e a própria cidade. Um vestido de mangas bufantes alegoriza a moda corrente na virada do século, contudo idealizado a partir de um inverossímil tecido leve e drapeado, cuja referência parece classicizante. Este vestido é preso por um cinturão sobre o qual vê-se a fênix, símbolo presente no brasão da cidade. Ainda a partir do brasão, Bernardelli atribuiu a figura uma coroa mural e um manto que envolve o colo da estátua, todo estampado por ramos de café em relevo.

\section{A apoteose de Carlos Gomes no Vale do Anhangabaú}

Uma homenagem a Carlos Comes estava aprovada na Câmara Municipal desde 1909, mas a empreitada contava com recursos escassos e pouca movimentação, até que membros da colônia

\footnotetext{
15 SIIVA, Maria do Carmo C. da. Op. cit., p.120.

16 Michalski descreve uma tendência narrativa em voga na escultura monumental francesa após a queda de Napoleão III e sinaliza para a aproximação entre estas obras e a tradição das pinturas históricas. Destaca a formação de um espaço cênico para os retratados, como, em um exemplo extremo, na escultura de Marat, de Jean Baffier (1887), representado escrevendo na banheira (destruído durante a ocupação nazista da França na grande coleta de metais para fins bélicos). MICHALSKI, Sergiusz. Public Monuments: art in Political Bondage (1870-1997). Londres: Reaktion Books, 1998, p. 25-26.

17 Uma reprodução pode ser vista no artigo da revista Renascença. Op.cit., p.52.
} 
italiana em São Paulo se propuseram a levar o projeto adiante ${ }^{18}$. A trajetória de sucesso do compositor brasileiro na Itália era conveniente para representar o ideal de uma aliança cultura e empreendedora entre os países, portanto ficou acertado que o monumento seria um presente para a cidade no contexto das celebrações do Centenário de Independência, em 1922.

O projeto ficou a cargo do escultor italiano Luigi Brizzolara, que estava em São Paulo como participante do concurso internacional para o Monumento a Independência, posteriormente inaugurado no Ipiranga. Neste concurso, Brizzolara foi derrotado por outro italiano, Ettore Ximenes, mas a disputa havia sido acirrada entre os dois favoritos. Desfrutando, portanto, do prestígio angariado com o segundo lugar, Brizzolara foi acionado para diversos projetos menores ${ }^{19}$, como o próprio Monumento a Carlos Comes.

Mas a indicação do italiano foi alvo de diversas críticas até mesmo por parte da imprensa da colônia, na qual sugeriu-se que a escolha de um nome ítalo-brasileiro - e havia muitos candidatos possíveis - teria sido um gesto mais coerente a ocasião, porém a comissão do monumento teria caído na "rotina de dar obras para uma celebridade europeia" ${ }^{20}$. Frequentemente a predileção por artistas estrangeiros era entendida como sinônimo do servilismo das elites do país.

Toda a trajetória de Luigi Brizzolara é bastante exemplar do sistema artístico transnacional surgido em torno da escultura monumental e notavelmente impulsionado pelos concursos públicos internacionais. Por isso o artista atuou em São Paulo, Rio de Janeiro, Buenos Aires e Caracas. Contudo, apesar da notável produção advinda deste sistema, o fato de que estes artistas estabeleciam suas carreiras em trânsito, muitas vezes fez suas atividades serem vistas como predatórias. Entre os muitos desdobramentos disso, o fato dessas obras permanecerem às margens dos interesses de uma historiografia da arte marcada por valores eminentemente nacionalistas.

O Monumento a Carlos Comes seria posicionado na praça lateral ao Teatro Municipal de São Paulo, na área do Parque do Anhangabaú. Era um local nobre, o principal cartão postal da cidade, símbolo de seu processo de modernização e embelezamento nas primeiras décadas do século XX. Mas o terreno oferecia dificuldades, era uma área com acentuado declive onde se encontrava uma escadaria de acesso ao Parque [Fig. 8] e uma fonte com uma estátua ornamental representando Netuno e tritões.

\footnotetext{
18 LOPES, F. op.cit., p. 68.

19 A exemplo de algumas obras para o cemitério da Consolação e os dois bandeirantes em mármore que adornam o átrio do Museu Paulista. Um levantamento das obras de Brizzolara foi apresentado a minha dissertação de mestrado (anexos). Idem.

20 Il Pasquino Coloniale, São Paulo, 29 de maio de 1920.
} 
Brizzolara concebeu um conjunto de 12 esculturas distribuídas em três níveis. Optou por explorar as características da área e apropriou-se de toda arquitetura pré-existente. Muitos estranharam a ausência de uma estrutura integrada para as diversas peças do monumento, considerando seu aspecto excessivamente fragmentado e pouco hierárquico. Um crítico, escrevendo para a Folha da Noite, afirmou que as figuras espalhadas a esmo perdiam em monumentalidade, parecendo um presépio de casa rica ${ }^{21}$.

De fato, Brizzolara inovava dispondo diversas de suas estátuas, compostas em tamanho pouco maior que o natural, ao nível do espectador, sem pedestal. Desta forma estão dispostos os bronzes que representam personagens das óperas do compositor: Fosca, Schiavo, Maria Tudor, Condor, Salvador Rosa e Guarany. O monumento incluiu também uma fonte ornamental com uma Clória galopando três cavalos fantásticos, alados e com nadadeiras nos cascos, simbolizando a travessia do Atlântico por Gomes. E ainda duas alegorias representando a Monarquia Italiana e a República Brasileira, a frente do conjunto.

De fato, muito haveria a ser disto sobre cada uma destas estátuas e a maneira como foram distribuídas, mas dado a brevidade deste artigo, vamos nos concentrar no retrato de Carlos Comes, que coroa o conjunto. Este retrato, além de ocupar a parte superior do terreno, no mesmo nível ao Teatro, foi posicionado sobre um pedestal que satisfazia a todas as convenções da monumentalidade oitocentista e que, no mais, se fazia necessário em face a enormidade da própria fachada do teatro ao fundo. Carlos Comes aparece ladeado por duas musas que representam a Música e a Poesia, que são as únicas figuras em mármore do conjunto.

Em geral, a recepção a obra de Brizzolara foi favorável, por vezes com elogios enfáticos como "um dos mais belos da América do Sul” "22 ", afirmação do modernista Menotti del Picchia e "o mais belo que existe hoje entre nós" ${ }^{23}$, exclamação de Monteiro Lobato. Para a comunidade italiana, o jubilo teria sido total com o sucesso do monumento, não fosse um episódio de fato insólito marcou a história do retrato de Carlos Comes: a decapitação da escultura, que recebeu uma segunda versão em 1926 [Fig. 9 e 10]. Isso porque já na inauguração a efígie do compositor causou desconforto. O público não o achava semelhante o bastante a Carlos Comes, ou pelo menos a sua imagem consagrada na memória coletiva. Luigi Brizzolara prometeu quase imediatamente a revisão do retrato, o que

\footnotetext{
21 "O Monumento a Carlos Gomes", Folha de Noite, São Paulo, 18 dezembro 1922, p.1.

22 HELIOS (Menotti del Picchia), Um monumento, Correio Paulistano, São Paulo, 13 outubro 1923, p. 4. Embora o escritor fizesse ressalvas ao monumento, sua opinião acerca do polêmico retrato de Carlos Comes foi elogiosa.

23 Monumentos, Revista do Brasil, n. 83, novembro 922. Reeditado no livro: LOBATO, M. Críticas e Outras Notas. São Paulo, Editora Brasiliense, 1965, p.221-223.
} 
[Figura 8]

Fotografia do Parque do Anhangabaú e do Teatro

Municipal de São Paulo,

em 1916.

Arquivo do Estado/VE]A. Acesso em: 04 dez 2019. Disponível em: https://veja.abril.com.br/galeriafotos/memorias-de-um-senhor -paulistano-de-100-anos/
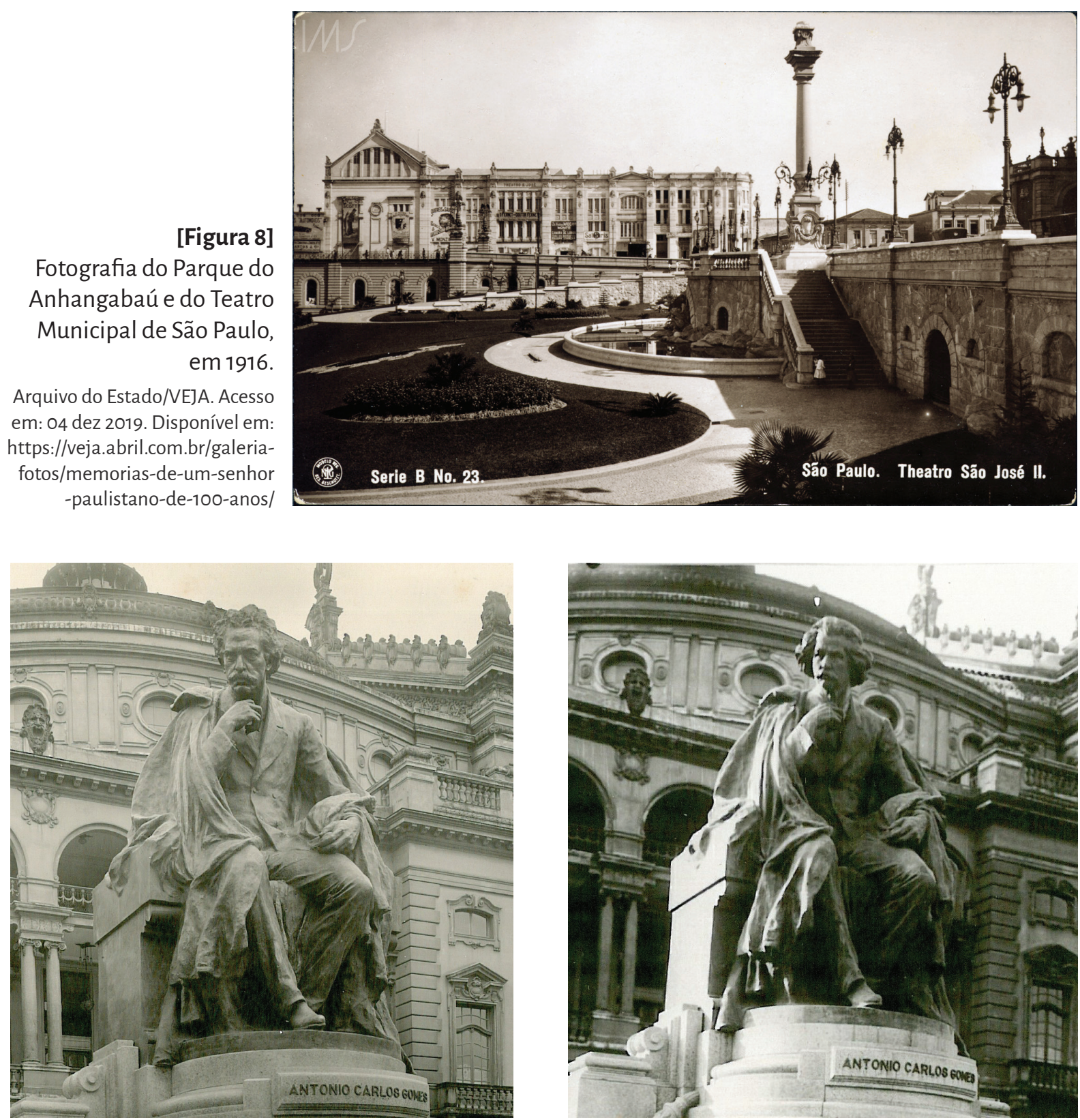

[Figuras 9 e 10] Luigi Brizzolara. Primeira e segunda versões para o retrato de Carlos Comes. Anos 1920. Fotografias pertencentes ao acervo da família do escultor (Graffigna-Brizzolara, Chiavari).

[Figra 11]

Rodolfo Bernardelli. Detalhe do retrato de Carlos Comes, ainda em gesso, para o monumento Campineiro. Reproduzido em: In: PINTO, Manuel de Souza. O Monumento a Carlos Gomes, in: Renascença, Rio de Janeiro, ano II, n. 13, agosto de 1905.

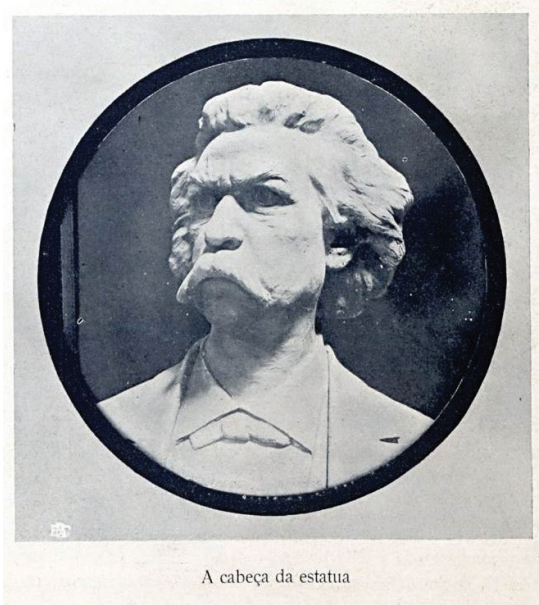


evitou maiores conflitos, mas não foi o suficiente para escapar da chacota. Os menos severos eximiram de culpa o escultor, afirmando que a referência entregue a Brizzolara teria sido imprópria. Nas entrelinhas entendeu-se, contudo, um problema maior por trás do malfeito: o escultor estrangeiro, estranho a nossa cultura, revelou-se inadequado a prestar homenagens ao prócer brasileiro ${ }^{24}$.

É evidente que o escultor italiano buscou, conscientemente, dar uma feição autêntica para o seu Carlos Comes, contrapondo-se ao monumento de Campinas. Neste último, "o semblante quase selvagem, de aspecto leonino"25, ao qual todos estavam habituados, foi fielmente observado (o adjetivo leonino é utilizado para descrever a figura de Carlos Comes desde seus anos na Itália). O maestro de Bernardelli apresentava sua notória cabeleira, os bigodes igualmente fartos e a baixa estatura, além de um gestual notavelmente pantomímico, narrativo, ao qual já nos referimos anteriormente [Fig. 11]. Em contraposição, Brizzolara escolheu retratar o compositor sentado em uma postura sóbria e dignificada, com uma silhueta alongada, esbelta e elegante - ainda mais evidente quando observamos a primeira versão do retrato. Sobre os ombros do músico, repousa um manto, que amplifica a figura através deste vasto planejamento sem, contudo, perturbar os atributos naturalistas da estátua.

Vale ressaltar que, na obra de Luigi Brizzolara, o retrato de Carlos Comes triunfa numa composição apoteótica. Possivelmente, enquanto refletia sobre as soluções que poderia dar para o espaço do Vale, vislumbrou potencializá-lo a partir de uma composição que, por definição, é ascendente. A comparação com o quadro Apoteose de Homero (1827), de Ingres [Fig. 12], é reveladora dessa gramática, ordenada na pintura pela presença da escadaria. Outros elementos recorrentes são a própria alegoria a Glória, musas e a personificação das obras do homenageado. São ainda comparáveis em outros aspectos, mais casuais, mas não menos instigantes, como a grande consonância entre a forma das alegorias aos pés dos artistas em ambas as obras, o contraponto das figuras a uma arquitetura monumental e significante, o templo e o teatro [Fig. 13], ou a repetição simbólica da lira e do pergaminho, ofertados a Homero por Píndaro e Sófocles, respectivamente, e que são empregados nas musas da Música e da Poesia. Caberia ao público a função de render homenagem, geração após geração, a Carlos Comes, substituindo os demais retratos presentes na pintura sobre Homero.

O fato é que em meio a um conjunto escultórico tão extenso e complexo, o despojamento

\footnotetext{
24 Ainda assim, a rendição de Brizzolara para Carlos Comes, encontrou aliados - Lobato foi um deles, no texto já referido. Mas o deboche prevalecia, particularmente impulsionado pela semelhança entre o retrato com o malfadado político José Comes Pinheiro Machado, cuja atuação polêmica havia cessado, em 1915, com um brutal assassinato. 25 OMEGNA, Omegna. Retrato de Carlos Comes, In: Revista do Centro de Ciências, Letras e Artes, ano XXII, n.56, p. 37.
} 


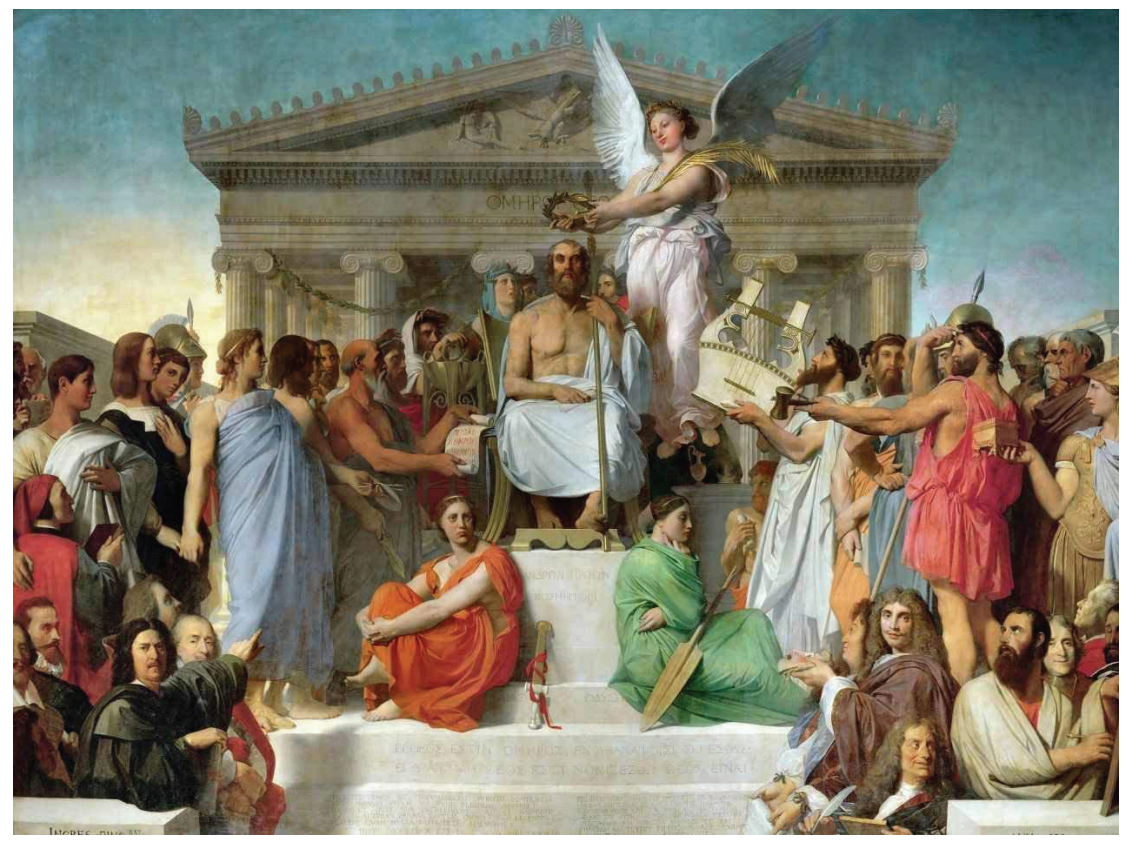

\section{[Figura 12]}

Jean Auguste Dominique Ingres. Apoteose de Homero, 1827.

Óleo sobre tela, 3,86 m x 5,12m, Museu do Louvre, Paris.

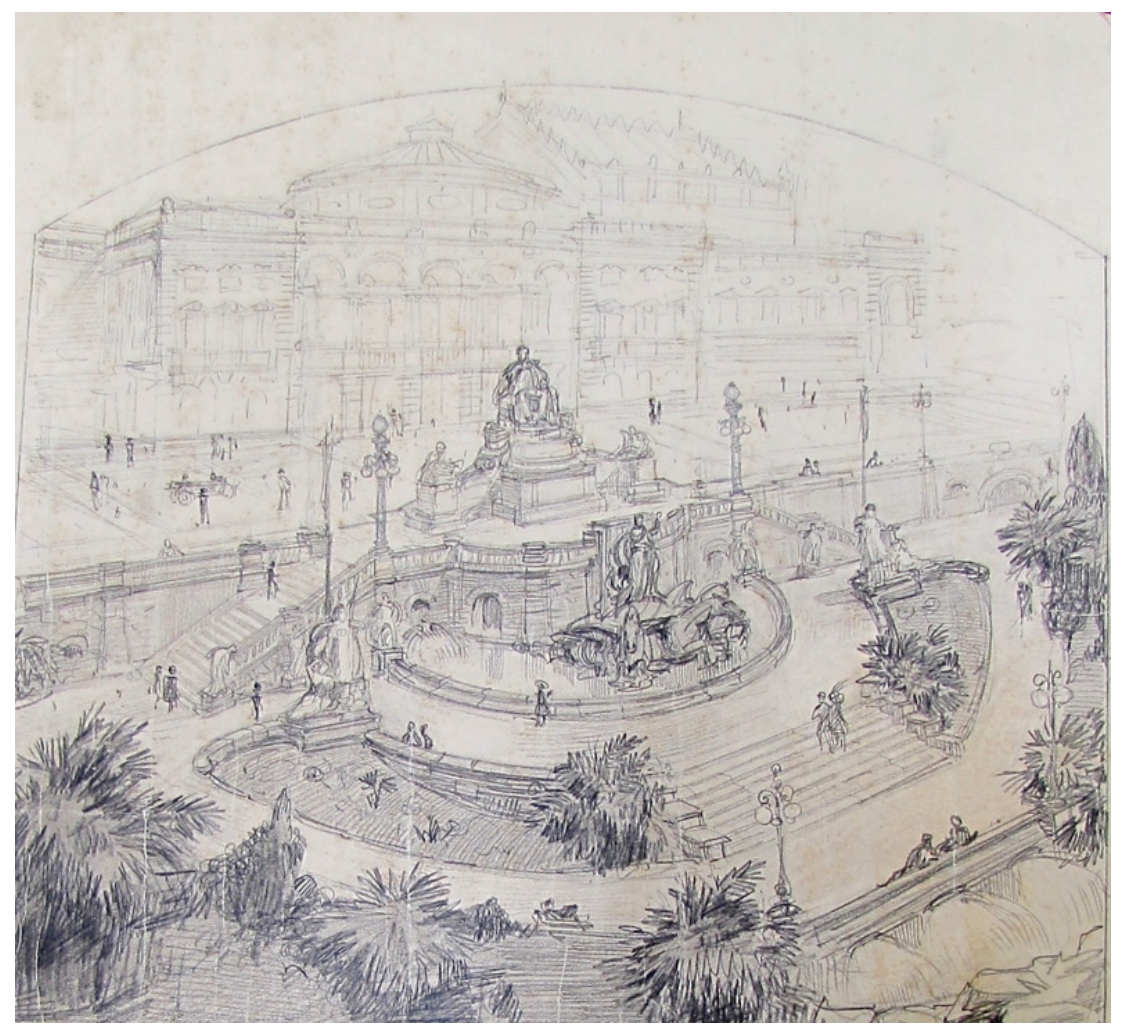

[Figura 13] Proposta para instalação das esculturas do Monumento a Carlos Gomes (1922).

Arquivo Histórico Municipal Washington Luís.

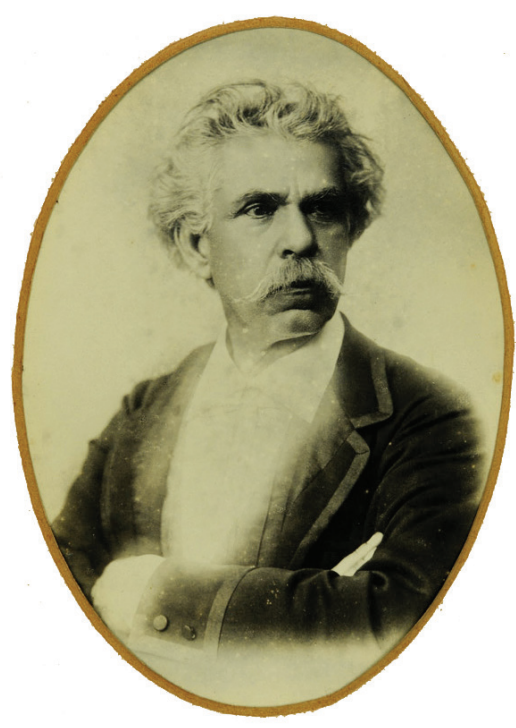

[Figura 14] Fotografia de Antonio Carlos Comes, sem data.

Coleção Carlos Comes, Museu Imperial. 
naturalista do retrato do compositor se impunha como uma opção apropriada. Além do mais, era um retrato com ares modernos e, talvez, levemente anacrônicos, mas em sintonia com o discurso de progresso cosmopolita almejado pela sociedade paulistana de 1922. Não era o rosto de Pinheiro Machado, nem acredito que Brizzolara deve ser acusado de ser um mal fisionomista. De fato, sua escolha pode ser referida em uma série de fotografias de Carlos Comes [Fig. 14], o que realmente não importava: o escultor pecou ao atentar contra os cabelos indomáveis do gênio de aparência leonina, alheio a forte presença deste rosto no imaginário social da Primeira República.

\section{Referências Bibliográficas}

CARBONCINI, Anna. Virada do Século - a escultura italiana em São Paulo. In: Dezenovevinte: uma Virada no século. São Paulo: Pinacoteca do Estado, 1986, p.11-15.

KNAUSS, P. O descobrimento do Brasil em escultura: imagens do civismo. Projeto História, São Paulo, v. 20, 2000, p. 178. Acessado em 11 out 2019. Disponível em: https://revistas.pucsp.br/revph/article/view/10810.

LOPES, Fanny. Cenografia e Paisagem Urbana: um estudo de caso na cidade de São Paulo. Dissertação (Mestrado em História) - Instituto de Filosofia e Ciências Humanas, Universidade Estadual de Campinas, Campinas, 2012.

MICHALSKI, Sergiusz. Public Monuments: art in Political Bondage (1870-1997). Londres: Reaktion Books, 1998, p. 2526.

OLIVEIRA, Emerson D. G. de. Os últimos dias de Carlos Comes: do mito gomesiano ao nascimento de um acervo. Revista CPC, São Paulo, n.4, maio/out. 2007, p.87-113.

OMECNA, Nelson, Retrato de Carlos Comes, In: Revista do Centro de Ciências, Letras e Artes, ano XXII, n.56, p. 37.

PINTO, Manuel de Souza. O Monumento a Carlos Comes, in: Renascença, Rio de Janeiro, ano II, n. 13, agosto de 1905 , p. 46.

SILVA, Maria do Carmo Couto da. Rodolfo Bernardelli, escultor moderno: análise da produção artística e de sua atuação entre a Monarquia e a República. Tese (doutorado em História) - Instituto de Filosofia e Ciências Humanas, Universidade Estadual de Campinas, Campinas, 2011. 